\title{
Internet Motives of Users in Jordan, UAE and KSA: A Cross-Cultural Validation of the Web Motivation Inventory (WMI)
}

\author{
Hamza S. Khraim ${ }^{1}$ \\ ${ }^{1}$ Department of Marketing, Faculty of Economics and Administrative Sciences, Zarqa University, Jordan \\ Correspondence: Hamza S. Khraim, Department of Marketing, Faculty of Economics and Administrative \\ Sciences, Zarqa University, P. O. Box 132222, Zarqa 13132, Jordan. E-mail: hkhraim@zu.edu.jo
}

Received: January 13, 2016

Accepted: February 19, 2016 Online Published: March 25, 2016

doi:10.5539/ijms.v8n2p138

URL: http://dx.doi.org/10.5539/ijms.v8n2p138

\begin{abstract}
The aim of this study is to replicate the Web Motivation Inventory (WMI) in new context. To date, the scale has only been tested on consumers in the United States, United Kingdom, Australia and South Korea. This research replicates the WMI using consumers from three Arab countries namely Jordan, UAE, and KSA. Results show that the same four-factor structure has been produced for the three countries, providing evidence of the scales cross cultural stability. Additional results show that there were differences in the four motives; research, communicate, surf, and shop in the three countries.
\end{abstract}

Keywords: internet motives, Web Motivation Inventory, Arab countries

\section{Introduction}

The internet has become a mainstream in everyday communications and transactions. In Arab region we are talking about 135 million users on internet, with 71 million using social media. This new trend in technology can lead to new aspects of Arab lifestyle and new business patterns, and it can create new opportunities and challenges for companies, consumers, and governments as well. The economic impact of Internet growth in the Arab region will only increase going forward. For example, in 2020, it is estimated that around 20 percent of the labor market in the Middle East will be related to internet and technology industries (The World Bank, 2014).

Without doubt, the benefits offered by the Internet to business and non-business institutions are innumerable. These advantages are not restricted for conducting businesses in a cost-effective and practical manner, but also it can reach consumers and society at large. For example, companies can conduct a lot of marketing research on new product development, market segmentation to serve customers better, and to distribute products faster as well as to open its communication channels online for any feedback or complain by its customers. Furthermore, Internet can play a very important role in managing the logistic issues with business partners by enhancing the flow of information, upgrading new products and customer services, and improved market transparency. According to (Rettie, 2002) Internet marketers who understand the motives of consumers from different countries can make better use of this global medium since culture affects perception, attitudes, behavior and ultimately, responsiveness to marketing activity. Although most of the empirical research on internet users' motives has focused on US consumers, some empirical studies have looked at other countries in addition to understanding Internet motives cross-culturally; there are calls for more replications in marketing (Hubbard \& Armstrong, 1994). According to Hunter (2001) replication studies are needed to examine the validity of motivation as a theoretical construct. Internet marketers who understand the motives of consumers from different countries can make better use of this global medium since culture affects perception, attitudes, behavior and ultimately, responsiveness to marketing activity (Rettie, 2002). Aladwani (2003) assert that it is no exaggeration that we know very little about the state of the Internet in the Arab world and more so in some parts of it. This study will help in filling the gap in understanding the motives of Arab consumers for using the Internet.

\subsection{Web Motivation Inventory WMI}

The WMI is the product of a series of studies that took place over a five-year period between 1997 and 2001. The WMI was developed in the United States and has only been tested on U.S. consumers (Rodgers \& Sheldon, 2002). Rodgers \& Sheldon (2002) identified four primary motivations for Internet use, which included researching, communicating, surfing, and shopping, and identified 12 items to assess the four motives (three 
items for each motive). The WMI has since been tested and retested and has been shown to organize Internet motives into four reliable and valid factors including shop, research/acquire information, communicate/socialize, and surf.

Rodgers et al. (2005) extends this work by replicating the Internet motives scale, the Web Motivation Inventory, in four countries: the United States, United Kingdom, Australia, and South Korea. The results revealed the same four-factor structure across the three English-speaking countries, providing evidence of the scale's global stability. Regarding South Korean sample, only three factors were initially generated. The initial analysis showed that the surf and research items loaded on the same factor. Results also show that the four motives; research, communicate, surf, and shop-differed significantly among the countries.

Again in Rodgers et al. (2007) tried to validate and extend the original Web Motivation Inventory (WMI). This study was different because new items as been added to the inventory to see if a new dimensions will be added to the original internet motives which include: research, communication, surfing and shopping. They examined the scale psychometric properties with two studies, the first study replicated the WMI with samples from the US, UK and Australia, and second study replicated and extended the WMI with three new samples from the same three countries. The results provide support for the psychometric soundness of the original WMI and the extended WMI. The original WMI was shown to be valid and reliable with US and non-US samples with somewhat different market and consumer settings, suggesting that the WMI is a culturally neutral scale that may be useful in a global environment. The extended WMI yielded 12 new sub-motives that proved to be adequate extensions of the original four-factor scale, providing additional evidence of the scale's unidimensionality, validity and reliability.

According to the researcher knowledge and up to date, no any research was conducted on internet users' motives in Arab countries. Therefore, the purpose of the present research is to fill in this gap and to contribute to the body of knowledge concerning this important issue in three Arab Countries namely UAE, KSA and Jordan.

\section{Importance and Objectives of the Study}

The importance of this study appears from the emerging trends towards the Internet use in Jordan, UEA and KSA as part of the world-wide Internet movement in recent years. There are only few studies that dealt with the issues of Internet motives in the Arab World. There is also a lack in studies that cover the issues of motives and technology, including the use of the Internet in general. We hope that this study will serve as a prelude to other studies and will provide new horizons for scientific research in Arab countries. Finally, the study also aims at determining and the extent of the benefit gained by consumers from the use of the internet.

The main objectives of this research paper are:

1) To identify the factors that motivates Jordanian, UAE, and KSA consumers for using the internet.

2) To examine if there is any differences in the motives of using the internet between Jordanian, UAE, and KSA consumers.

3) To examines the motives of using the internet by consumers in an effort to minimize the discrepancies between academic developments and real world practice.

\section{Literature Review}

\subsection{Classification and Typology of Internet Motives}

Although scholars highlight some problems in the conceptualization and classification of motives, a number of researchers in the past ten years have proposed different classifications of internet activities, their underlying motives, as well as Internet user types. The classifications are based on different criterion and tend to vary in terms of the applied theories, as well as the sampling and measurement techniques. Some studies have apply the uses-and-satisfaction scheme, which indicate how people embrace and use communication media as a tool of their emotional needs and the satisfaction they seek (Kim et al., 2011). While Horrigan (2007) points out that many studies and due to lack of clear theoretical insight used the inductive explorative scheme to categorize online activities. While typologies used in studying internet motives enclose difference as well. For instance, some researchers have used different criterion to depict differences between the use of online social, leisure, and information services (Hamburger \& Ben-Artzi, 2000), while Landers \& Lounsbury (2006) used motives such as social, leisure, and academic Internet use, whereas Swickert et al. (2002) have employ different classification method for drawing distinction by using technical, information exchange, and leisure motives. Furthermore, Gombor \& Vas (2008) has emphasized that motives for Internet use are often found to be culture-specific. 
Recently, many studies have been carried out to propose more generalized classifications of motives for Internet use and user types. For example, some studies have argued that the main originator for motivations underlying the use of the Internet comprise information, convenience, entertainment, and social interaction (Kim et al., 2011). Brandtzæg (2010) conducted a meta-analysis of 22 previous studies, proposing a unified Media-User Typology, and to be universal across different cultures.

\subsection{Internet in the Arab World}

Arab countries are similar in many ways including religion, customs and values, history, and language. However, we contend that the Arab world differ mainly in terms of wealth. Most Arab countries do not have access to sufficient wealth and resources except for all Arab Gulf countries. The average GDP per capita of Arab Gulf countries exceeds that of the world average and some advanced countries, while the average GDP per capita of other Arab countries either equals that of least developed countries in the world or approximately equal the world's average. With regards to internet in the Arab world, there are more than 100 Internet service providers in operation in Arab countries providing several services. The monopoly in the Internet market raises the cost of an Internet connection in most Arab countries and to some extent helps in the deterioration of the service (Aladwani, 2003).

Most Middle East countries, in general, and the GCC countries, in particular, continue to invest heavily in their ICT infrastructure as a part of economic development, including technologies intended to overcome ICT infrastructure hindrances and to enhance Internet access through WiMAX, broadband, and 3G mobile technologies (Alqudsi-ghabra, 2011). According to Internet World Stats' latest data as shown in Table 1, as of November 2015, concerning the three countries under study, statistics show that UAE has the highest penetration rate of $93.2 \%$, while Jordan has $86.1 \%$ penetration rate, while in KSA the penetration rate was $65.9 \%$.

Table 1. Internet users, population and facebook statistics

\begin{tabular}{lllll}
\hline Country & Population & Internet Usage & \% Population & Facebook \\
\hline & (2015 Est.) & 30 -Nov-2015 & (Penetration) & 15-Nov-2015 \\
Jordan & $6,623,279$ & $5,700,000$ & $86.1 \%$ & $4,100,000$ \\
Saudi Arabia & $27,752,316$ & $18,300,000$ & $65.9 \%$ & $12,000,000$ \\
United Arab Emirates & $9,445,624$ & $8,807,226$ & $93.2 \%$ & $6,300,000$ \\
\hline
\end{tabular}

Source: Internet world stats. 2016, miniwatts marketing group.

\subsubsection{Jordan}

Internet services started in Jordan in 1995, at which time connectivity was principally in the hands of the government and academics. Rapidly, these efforts were privatized, and by the following year privileged users understood the role of the Internet in sustaining the economy. This interest fostered the development of a national information system as well as an attempt to link information-generating centers in both the public and private sectors. Telecommunication infrastructure and regulation has evolved to sustain the development of the Internet in Jordan. Several private ISPs have been granted permission to offer services, although all links must still pass through the government telecommunication hub. Individuals, corporations, and organizations are able to establish Internet accounts easily without government approval or registration. In 2001, the city of Irbid boasted 105 cybercafés on one street alone (Jordan Times, 2001). Despite the governement support, still there are problems that hamper the diffusion of the Internet in the country. Firstly, Jordan is a relatively poor country where most citizens cannot afford the cost of a PC, modem and Internet subscription. Secondly, all Jordanian ISPs are located in the capital city of Amman, restricting access to urban users and facilitating greater government control over ISPs. Access points outside Amman are only available through slow and expensive long-distance dial-up.

\subsubsection{United Arab Emirates}

The UAE has a well-developed and technologically advanced telecommunications infrastructure and has high mobile telephone and Internet penetration. About 51.2 per cent of internet users in the UAE reported purchasing products and services online and through their mobile handsets over the past 12 months (Gulf News, 2007). Majority government-owned Emirates Telecommunication Corporation Ltd (Etisalat) operates, maintains and 
develops the national and international fixed-line network, mobile telephony, Internet access and cable TV services but its monopoly has been cancelled. The company has been increasing its presence in numerous countries. Broadband Internet connections are available by Digital Subscriber Line (DSL) and cable, with DSL line numbers growing quickly.

\subsubsection{Saudi Arabia}

In 1999 Saudi Arabia exposed itself to the Internet. In September 1999, the number of the Saudi Internet subscribers reached 45,000, making the number of users 135,000 if each subscription is used by 3 users. The Saudi government encourages Internet use because it believes that increased Internet use will aid national development projects. To increase access and use of the Internet, the government has developed the country's communication infrastructure and increased the geographic coverage of Internet services. These initiatives have been successful: Internet users in Saudi Arabia increase to 18.3 million by 2015 .

About $40 \%$ of the information and communication equipment and programs imported to the Arab region go directly to the Saudi market. The Saudi information market's annual increase is about $15 \%$, making it the largest Arab market in terms of demand. The Saudi government made the Riyadh-based "King Abdel Aziz City for Science and Technology" (KACST) the sole institution responsible for Internet provision (Bo Holeqa, 2004). Finally, despite the fact that the Saudi government attempts to increase the number of Internet users, but on the other hand try to ban users to visit websites considered offensive like political, religious, or sexual websites. Table 1 describes UAE, KSA and Jordan characteristics

\subsection{Previous Work}

The most recent comprehensive report on Internet and social media was prepared by TNS (2015) with the aim of evaluating the perceptions of the users in the Arab world vis-à-vis social media, as well as describing their internet usage habits. The study use both qualitative research and a quantitative survey: The qualitative research module was conducted on a regional level (GCC Countries \& Yemen, the Levant \& Iraq and North Africa): Focus Group Discussions with active users of social media-In-depth Interviews with experts in relevant fields such as media / communications, economics, and government affairs. The quantitative survey was conducted via Telephone Interviews with a sample more than 7000 users of social media spread evenly across 18 Arab countries. The results show that social media in the Arab world is perceived as having numerous positive aspects that enhance the quality of life of individuals, and business profitability. More than half the users in the Arab World use social media primarily to connect with people. While gaining information, watching videos, listening to music and sharing photos came as the second top main reason for using social media.

While Al-Adaileh (2015) study aimed to measure the role of social networks in influencing the student's decision to buy by using the analytical technique to examine the relationship between the study variables. The sample consist of (524) student from Qassim University in KSA. Results indicate that the dimensions of social networking (Information Exchange, product Rating) have a significant impact in purchasing decision, while indicating no significant impact for customer support as one of the dimensions of social networking. In light of the findings, marketing managers must understand the functionality of social networking tools, and find out how to use them effectively and efficiently. And determine the social networking aspects that need to be improved, and to use the appropriate social networking tool.

Al-Saggaf (2013) examined the users' motives for using Al Arabiya site, which is one of the highly ranked sites in the Arab World. The results from a web-based survey indicate that information seeking, which accounted for $26.312 \%$ of the variance, was the most salient motive for using Al Arabiya site. The interpersonal utility, which came in second place and accounted for $25.541 \%$, was another important motive for users to access Al Arabiya site. However, the third factor, pass time, which accounted for $14.625 \%$ of the variance, was consistent with previous research. The findings of this study show that people used Al Arabiya site not only to find out what is happening in the Arab world but equally important to express their opinions freely, to participate in discussions and to provide supplementary information. This suggests that in countries where traditional media sources are controlled, the internet is largely censored and freedom of expression is limited, new media can significantly reduce the effects of these limitations.

Aldhaheri (2012) descriptive study focused on exploring if there is any differences in the way that Arab women use the internet in two countries (the UAE and Oman). Results show that there are few differences between the UAE women and Omani women in using internet and that both women are using internet every day between 1-4 hours daily. More specifically, the study has shown that both women use internet for different reasons such as sending and receiving e-mails, to find some information, to read newspaper, to chat with friends, and to learn some skills. The study found that there is a difference in using internet for expressing feeling between UAE 
women and Omani women. $80 \%$ of UAE women are using internet to express their feeling while $30 \%$ of women are using internet for the same reason. Both women are agreed that using internet helped them to understand women issues around the world.

Kalmus et al. (2011) study was to categorize factors that influence Internet use such as personality traits, socio-demographic variables, and indicators of habitus and lifestyle. To achieve this target the authors have develop empirical and interpretable classification of online activities as well as their underlying motives. Results of factor analysis of online activities produced two underlying motives for Internet use: Social media and entertainment (SME), and Work and information (WI). Younger age consumers with lower education level were more attracted to (SME) than any other groups; in addition they tend to use the internet more in different places such as public place, at friends and at home. While consumers with higher education level were more attracted for (WI) motives, it was best predicted by the frequency of Internet use at work or school, and more active civic participation. The driving force behind Internet use for SME appears to be personal need for communication, self expression, and entertainment, while WI pertains to structure-driven duties and obligations, as well as institutional roles (including familial roles).

While the aim of Muhtaseb \& Frey (2008) study was to understand Arab Americans' salient motives for using the internet and whether the internet served as a functional alternative to other media to satisfy Arab Americans' information-seeking and interpersonal needs. The findings from this study showed that Arab Americans used the internet to meet particular needs and that the internet served, for them, as a functional alternative to other media. The findings suggests that in terms of motives for using the internet, information seeking was the most salient motive for Arab Americans, followed by convenience, entertainment, pass time, and interpersonal motives. Whether these internet motives differ from those of other Americans is a difficult question to answer. Because this study did not compare the internet motives of this sample of Arab Americans with the motives of members of any other U.S. cultural groups.

\section{Research Methodology}

The main objective of this research paper is to understand the motives of using the internet in Jordan, UAE and KSA. To reach this objective, the Web Motivation Inventory (WMI) four primary Internet functions including Shopping, Surfing, Research, and Communication were included in the questionnaire. The respondents motives were measured on five-point Likert scale $(1=$ Strongly Disagree to $5=$ Strongly Agree). The questions were translated to standard Arabic language, the official language of the three countries, to ensure that all questions will be clear, back translation was done to ensure that questions will carry the same meaning. After conducting the pilot study on 20 students in the three countries, no significant differences was found in the meaning of the questions. Survey of the 12 items comprising the WMI was administered to undergraduate students at three universities: Jordan, MEU university $(N=150)$, UAE, Abu Dhabi University $(N=150)$, and KSA, Effat University $(N=150)$. It's noteworthy to say Effat University is designed for female students only, so all KSA sample will be female students. Data collection started mid 2013 and finished almost end of 2014. Students are an appropriate sample since they are heavy users of the internet and are adequate when research addresses methodological issues such as scale development and validation (Chen et al., 2002).

\section{Data Analysis}

\subsection{Sample Profile}

Data collected show that the majority of respondent in the three countries are from undergraduate students, while postgraduate student were the highest in KSA. While regarding age category, respondents between 21-25 years were the highest among other categories in the three samples, followed by 26-30 years. Finally, female students were the predominant in the sample because all KSA sample were female students. 
Table 2. Cross tabulation of respondents' profile

\begin{tabular}{llll}
\hline & Jordan & UAE & KSA \\
\hline Education & & & \\
Under graduate & $128(85.3 \%)$ & $112(74.7 \%)$ & $92(61.3 \%)$ \\
$\begin{array}{l}\text { Post graduate } \\
\text { Total }\end{array}$ & $22(14.7 \%)$ & $38(25.3 \%)$ & $58(38.7 \%)$ \\
\hline Age & $150(100 \%)$ & $150(100 \%)$ & $150(100 \%)$ \\
Less than 20 & & & \\
$21-25$ & $8(5.3 \%)$ & $21(14.0 \%)$ & $40(26.7 \%)$ \\
$26-30$ & $91(60.7 \%)$ & $118(78.7 \%)$ & $61(40.7 \%)$ \\
More than 31 & $42(28.0 \%)$ & $11(7.3 \%)$ & $45(30.0 \%)$ \\
Total & $9(6.0 \%)$ & $0(0.0 \%)$ & $4(2.7 \%)$ \\
Gender & $150(100 \%)$ & $150(100 \%)$ & $150(100 \%)$ \\
Male & & & \\
Female & $89(59.3 \%)$ & $59(39.3 \%)$ & $00(0.0 \%)$ \\
Total & $61(40.7 \%)$ & $91(60.7 \%)$ & $150(100.0 \%)$ \\
\hline
\end{tabular}

\subsection{Results}

In order to ascertain the latent variables and sample adequacy, Bartlett's results have supported the appropriateness of the observed data to the factor analysis $\left(\mathrm{KMO}=.719 ; \chi^{2}=400.942, \mathrm{df}=66, \mathrm{p}=.000\right)$. Data were analyzed using Factor Analysis followed by Varimax Rotation was used to test the dimensionality of the measure of a theoretical construct, and to make decisions about whether the scale is valid and reliable (Bollen \& Lennox 1991). Items with eigenvalues of 1.0 or higher and item loadings of 0.40 were retained (Nunnally \& Bernstein 1993). Factor analysis with a Varimax rotation produced the same four-factor structure for the three Arab countries (see Table 3, 4 and 5). Furthermore, reliability analysis was conducted using Cronbach Alpha $(\alpha)$ as a criterion for internal consistency at a minimum acceptable level (Alpha $\geq 0.60$ ) as suggested by (Sekaran, 2003). Results for the Jordanian sample of Internet motives and their alphas were: research $(\alpha=.64)$, communicate $(\alpha=.71)$, shop $(\alpha=.65)$, and surf $(\alpha=.68)$. The combined items explained 62 percent of the total item variance. While results for UAE sample of Internet motives and their alphas were as follows: research $(\alpha$ $=.62)$, communicate $(\alpha=.63)$, shop $(\alpha=.66)$, and surf $(\alpha=.70)$, which explained 67 percent of the total item variance. For the KSA sample, the resulting motives and their alphas were: research $(\alpha=.56)$, communicate $(\alpha$ $=.80)$, shop $(\alpha=.53)$, and surf $(\alpha=.83)$, which explained 64 percent of the total item variance. The high-reliability alpha for each motive for Jordan and UAE demonstrates good internal consistency of the WMI scale. While there was some weakness regarding Cronbach Alpha reliability of KSA sample dealing with shopping and research. Yet it's still considered accepted.

Table 3. Rotated factor pattern from principal component analysis of the WMI: Jordan sample

\begin{tabular}{|c|c|c|c|c|}
\hline Motives & Shop & Surf & Research & Communicate \\
\hline \multicolumn{5}{|l|}{ I use the internet to: } \\
\hline \multicolumn{5}{|l|}{ Shop } \\
\hline 1) Make a purchase & .736 & & & \\
\hline 2) Buy things & .701 & & & \\
\hline 3) Purchase a product I've heard about & .719 & & & \\
\hline \multicolumn{5}{|l|}{ Surf } \\
\hline 4) Explore new sites & & .640 & & \\
\hline 5) Surf for fun & & .807 & & \\
\hline 6) Find interesting web pages & & .765 & & \\
\hline \multicolumn{5}{|l|}{ Research } \\
\hline 7) Do research & & & .534 & \\
\hline 8) Get information I need & & & .845 & \\
\hline 9) Find out things I need to know & & & .718 & \\
\hline \multicolumn{5}{|l|}{ Communicate } \\
\hline 10) Email other people & & & & .838 \\
\hline 11) Connect with my friends & & & & .785 \\
\hline 12) Communicate with others & & & & .867 \\
\hline
\end{tabular}


Table 4. Rotated factor pattern from principal component analysis of the WMI: KSA sample

\begin{tabular}{|c|c|c|c|c|}
\hline Motives & Shop & Surf & Research & Communicate \\
\hline \multicolumn{5}{|l|}{ I use the internet to: } \\
\hline \multicolumn{5}{|l|}{ Shop } \\
\hline 1) Make a purchase & 50.9 & & & \\
\hline 2) Buy things & 73.2 & & & \\
\hline 3) Purchase a product I've heard about & 67.3 & & & \\
\hline \multicolumn{5}{|l|}{ Surf } \\
\hline 4) Explore new sites & & 81.5 & & \\
\hline 5) Surf for fun & & 47.6 & & \\
\hline 6) Find interesting web pages & & 65.5 & & \\
\hline \multicolumn{5}{|l|}{ Research } \\
\hline 7) Do research & & & 67.1 & \\
\hline 8) Get information I need & & & 71.0 & \\
\hline 9) Find out things I need to know & & & 47.9 & \\
\hline \multicolumn{5}{|l|}{ Communicate } \\
\hline 10) Email other people & & & & 82.3 \\
\hline 11) Connect with my friends & & & & 65.4 \\
\hline 12) Communicate with others & & & & 61.2 \\
\hline
\end{tabular}

Table 5. Rotated factor pattern from principal component analysis of the WMI: UAE sample

\begin{tabular}{|c|c|c|c|c|}
\hline Motives & Shop & Surf & Research & Communicate \\
\hline \multicolumn{5}{|l|}{ I use the internet to: } \\
\hline \multicolumn{5}{|l|}{ Shop } \\
\hline 1) Make a purchase & 79.8 & & & \\
\hline 2) Buy things & 79.5 & & & \\
\hline 3) Purchase a product I've heard about & 68.8 & & & \\
\hline \multicolumn{5}{|l|}{ Surf } \\
\hline 4) Explore new sites & & 74.2 & & \\
\hline 5) Surf for fun & & 77.9 & & \\
\hline 6) Find interesting web pages & & 72.5 & & \\
\hline \multicolumn{5}{|l|}{ Research } \\
\hline 7) Do research & & & 85.2 & \\
\hline 8) Get information I need & & & 69.6 & \\
\hline 9) Find out things I need to know & & & 63.0 & \\
\hline \multicolumn{5}{|l|}{ Communicate } \\
\hline 10) Email other people & & & & 70.6 \\
\hline 11) Connect with my friends & & & & 66.5 \\
\hline 12) Communicate with others & & & & 73.4 \\
\hline
\end{tabular}

To achieve the second objective of this study, for all four factors, we summed up the three items of each factor together to create four indices, one for each motive. This step was repeated for each of the three countries. The motives included shopping, surfing, researching, and communicating. The mean motive scores for each country can be found in Table 6. Findings reveal that Saudi consumers scored higher in term of shopping, research and surfing, while Jordanian consumers scored higher in term of communication.

Table 6. Comparison of means of factor scores

\begin{tabular}{lllll}
\hline & Shop & Surf & Research & Communicate \\
\hline Jordan & 4.18 & 4.13 & 4.30 & 4.16 \\
UAE & 3.72 & 3.93 & 3.80 & 4.04 \\
KSA & 4.28 & 4.16 & 4.43 & 4.07 \\
\hline
\end{tabular}

From the above table we can see that communications is considered as the most important motive in the three countries to use the internet. This emphasizes the importance of using the social media as a tool for communication by which marketers use as an important tool in advertisement. Both Jordan and KSA got a mean above 4.0 for the four motives, while concerning UAE, only communication got a mean above 4.0 while other 
factors were less than 4.0. Despite that surf and research can be an important step towards conducting other activities on the internet, which can be very important in exploring consumers' attitude and decision making.

\section{Conclusion}

The purpose of this research was to replicate the Web Motivation Inventory (WMI), which categories internet motives into four primary factors: research, communication, surfing and shopping. The scale's psychometric properties were examined by replicating the WMI with samples from three Arab countries, Jordan, UAE and KSA. The results presented here provide support for the psychometric soundness of the WMI. The WMI was shown to be valid and reliable with non-US samples with different market and consumer settings, suggesting that the WMI is a culturally neutral scale that may be useful in a global environment.

\section{Acknowledgment}

This research is funded by Deanship of scientific research and Graduate studies at Zarqa University, Jordan.

\section{References}

Al-Adaileh, M. J. A. (2015). The Role of Social Networks in Influencing the Purchasing Decision for Online Consumer: An Analytical Study inQassim University KSA. The Jordanian Journal for Business Administration, 11(1), 153-170.

Aladwani, A. M. (2003). Key Internet characteristics and e-commerce issues in Arab countries. Information Technology \& People, 16(1), 9-20. http://dx.doi.org/10.1108/09593840310462998

Aldhaheri, A. K. (2012). Arab Women Using Internet: Case Study the UAE and Oman. Journal of Mass Communication Journalism, 2(7), 618-657. http://dx.doi.org/10.4172/2165-7912.1000121

Alqudsi-ghabra, T. M., Al-Bannai, T., \& Al-Bahrani, M. (2011). The Internet in the Arab Gulf Cooperation Council (AGCC): Vehicle of Change. International Journal of Internet Science, 6(1), 44-67.

Al-Saggaf, Y. (2013). Arabs motives for using new media: a uses and gratifications perspective. The Asian Conference on Media and Mass Communication. Retrieved from www.iafor.org

Anita, G., \& Liliana, V. (2008). Differences between motives for Internet use and life satisfaction among Hungarian and Italian medical students. Retrieved from http://hej.sze.hu/INF/INF-080514-B/inf080514b.pdf

Bo, H., \& Ihsan, A. (2004). Al Hayat newspaper, 14947(29).

Bollen, K., \& Richard, L. (1991). Conventional Wisdom on Measurement: A Structural Equation Perspective. Psychological Bulletin, 110(2), 305-314. http://dx.doi.org/10.1037/0033-2909.110.2.305

Chen, Q., Clifford, S. J., \& Wells, W. D. (2002). Attitude toward the site II: new information. Journal of Advertising Research, 42(2), 33-45. http://dx.doi.org/10.2501/JAR-42-2-33-45

Gulf News. (2007). UAE internt users spend over $\$ 1.15 \mathrm{~b}$ on e-commerce. Retrieved from http://archive.gulfnews.com/articles/07/09/10/ 101526 13.html

Jayawardhene, C., Wright, L. T., \& Mastrrson, R. (2003). An Investigation of Online Consumer Purchasing. Qualitative Market Research: An International Journal, 6(6), 58-65. http://dx.doi.org/10.1108/13522750310457384

Jesse, W. J. W., \& Ton, V. R. (2007). E-shopping versus city center shopping: the role of perceived city center attractiveness. Tijdschrift Voor Economische En Sociale Geografie, 98(1), 68-85. http://dx.doi.org/10.1111/j.1467-9663.2007.00377.x

John, B. H. (2007). A typology of information and communication technology users. Pew Internet \& American Life Project Report. Retrieved from http://www.pewinternet.org/ /media//Files/Reports/2007/PIP_ICT_Typology.pdf

Jong-Youn, R. (2003). Consumers in the Internet Era: Essays on the Impact of Electronic Commerce from a Consumer Perspective. Consumer Interests Annual, 49(3).

Jonna, J., \& Jussi, P. (2004). Distrust of One's Own Web Skills: A Reason for Offline Booking after Online information Search. Electronic Markets, 14(4), 333-343. http://dx.doi.org/10.1080/10196780412331311775

Kim, Y., Dongyoung, S., \& Sejung, M. C. (2011). Cultural difference in motivations for using social network sites: a comparative study of American and Korean college students. Computers in Human Behavior, 27(1), 365-372. http://dx.doi.org/10.1016/j.chb.2010.08.015 
Muhtaseb, A., \& Lawrence, R. F. (2008). Arab Americans' Motives for Using the Internet as a Functional Media Alternative and Their Perceptions of U.S. Public Opinion. Journal of Computer-Mediated Communication, 13, 618-657. http://dx.doi.org/10.1111/j.1083-6101.2008.00413.x

Petter, B. B., Jan, H., \& Amela, K. (2011). Understanding the new digital divide-a typology of Internet users in Europe. International Journal of Human-Computer Studies, 69(3), 123-138. http://dx.doi.org/10.1016/j.ijhcs.2010.11.004

Raymond, H., \& Scott, J. A. (1994). Replications and Extensions in Marketing: Rarely Published but Quite Contrary. International Journal of Research in Marketing, 11(3), 233-248. http://dx.doi.org/10.1016/0167-8116(94)90003-5

Richard, N. L., \& John, W. L. (2006). An investigation of Big Five and narrow personality traits in relation to internet usage. Computers in Human Behavior, 22(2), 283-293. http://dx.doi.org/10.1016/j.chb.2004.06.001

Rodgers, S., \& Sheldon, K. M. (2002). An improved way to characterize internet consumers. Journal of Advertising Research, 42(5), 85-94. http://dx.doi.org/10.2501/JAR-42-5-85-94

Rodgers, S., Yan, J., Ruth, R., Frank, A., \& Doyle, Y. (2005). Internet Motives of Users in the United States, UK, Australia, and Korea: A Cross-Cultural Replication of the WMI. Journal of Interactive Advertising, 6(1). http://dx.doi.org/10.1080/15252019.2005.10722108

Rodgers, S., Ye, W., Ruth, R., \& Frank, A. (2007). web motivation inventory: replication, extension and application to internet advertising. International Journal of Advertising, 26(4), 447-476.

Ruth, R. (2002). Net Generation Culture. Journal of Electronic Commerce Research, 3(4). Retrieved from http://www.csulb.edu/web/journals/jecr/p_i.htm

Swickert, J., James B., Jamie L., \& Jennifer, A. (2002). Relationships among Internet use, personality and social support. Computers in Human Behavior, 18(4), 437-451. http://dx.doi.org/10.1016/S0747-5632(01)00054-1

Teemu, Y. (2005). A sequence analysis of Consumers' online Searches. Internet Research Journal, 15(2), 181-194. http://dx.doi.org/10.1108/10662240510590351

The World Bank. (2014). Broadband Networks in the Middle East: Accelerating High-Speed. Retrieved from http://www.worldbank.org/en/region/mena/publication/broadband-networks-in-mna

TNS (Taylor Nelson Sofres). (2015). Arab Social Media Report.

Uma, S. (2003). Research Methods for Business. New York: John Wiley \& Sons.

Veronika, K., Realo, A., \& Andra S. (2011). Motives for internet use and their relationships with personality traits and socio-demographic. TRAMES, 15(4), 385-403. http://dx.doi.org/10.3176/tr.2011.4.04

Wright, L., \& Jayawardhena, C. (2001). Netting the consumer: the e-direct marketing imperative, CD-Rom. Proceedings of the Marketing Science Conference, University of Cardiff, Wales, June-July.

Yoo-Kyoung, S., \& Marjorie, N. (2007). Attitude toward internet web sites, online information search, and channel choices for purchasing. Journal of Fashion Marketing and Management, 11(4), 571-586. http://dx.doi.org/10.1108/13612020710824616

\section{Copyrights}

Copyright for this article is retained by the author, with first publication rights granted to the journal.

This is an open-access article distributed under the terms and conditions of the Creative Commons Attribution license (http://creativecommons.org/licenses/by/3.0/) 